\title{
Cushing's syndrome due to primary pigmented nodular adrenal disease in two brothers with Carney complex
}

Zespół Cushinga z powodu pierwotnej pigmentowej choroby guzkowej nadnerczy u dwóch braci z zespołem Carneya

\author{
Bhawna Attri, Anshita Aggarwal, Sahil Mattoo, Bindu Kulshreshtha
}

Department of Endocrinology, Atal Bihari Vajpayee Institute of Medical Sciences and Dr. Ram Manohar

Lohia Hospital, New Delhi, Delhi, India

\begin{abstract}
Two brothers (19 and 18 years old, respectively) presented with weight gain and stunted growth since the age of 10 years. They had spotty skin pigmentation over the face along with florid features of Cushing's syndrome with low bone density, renal calculi, dyslipidaemia, hypertension, and dilated cardiomyopathy. They underwent evaluation of the hypothalamic-pituitary-adrenals axis, which suggested ACTH-independent Cushing's syndrome, and the abdominal CT imaging revealed normal adrenals. The diagnosis of Familial Cushing's syndrome with primary pigmented nodular adrenal disease and Carney complex was made. Bilateral adrenalectomy was carried out in both of them with resolution of the features of hypercortisolaemia post-operatively.
\end{abstract}

Key words:

PPNAD, Carney complex, Cushing's syndrome. 


\section{Introduction}

Primary pigmented nodular adrenal disease (PPNAD) is a disease characterised by adrenocorticotropin (ACTH)-independent micronodular adrenal hyperplasia. It constitutes $<1 \%$ of all cases of Cushing's syndrome (CS) [1]. Most cases are associated with Carney complex (CC) (autosomal dominant mode of inheritance). It presents in patients $<30$ years of age, and $50 \%$ of cases are $<15$ years of age. Bilateral adrenalectomy is curative. We report cases of two brothers having CS due to PPNAD as a part of CC.

\section{Case report}

\section{Case 1}

A 19-year-old boy presented to us with complaints of weight gain and stunting since 10 years of age. He gave a history of easy bruising of the skin, red-purple stretch marks over the abdomen, and difficulty in lifting heavy objects. He had a history of recurrent renal calculi. He denied steroid intake. He had a younger brother with similar complaints. He had hypertension, moon-shaped face, facial plethora, centripetal obesity,

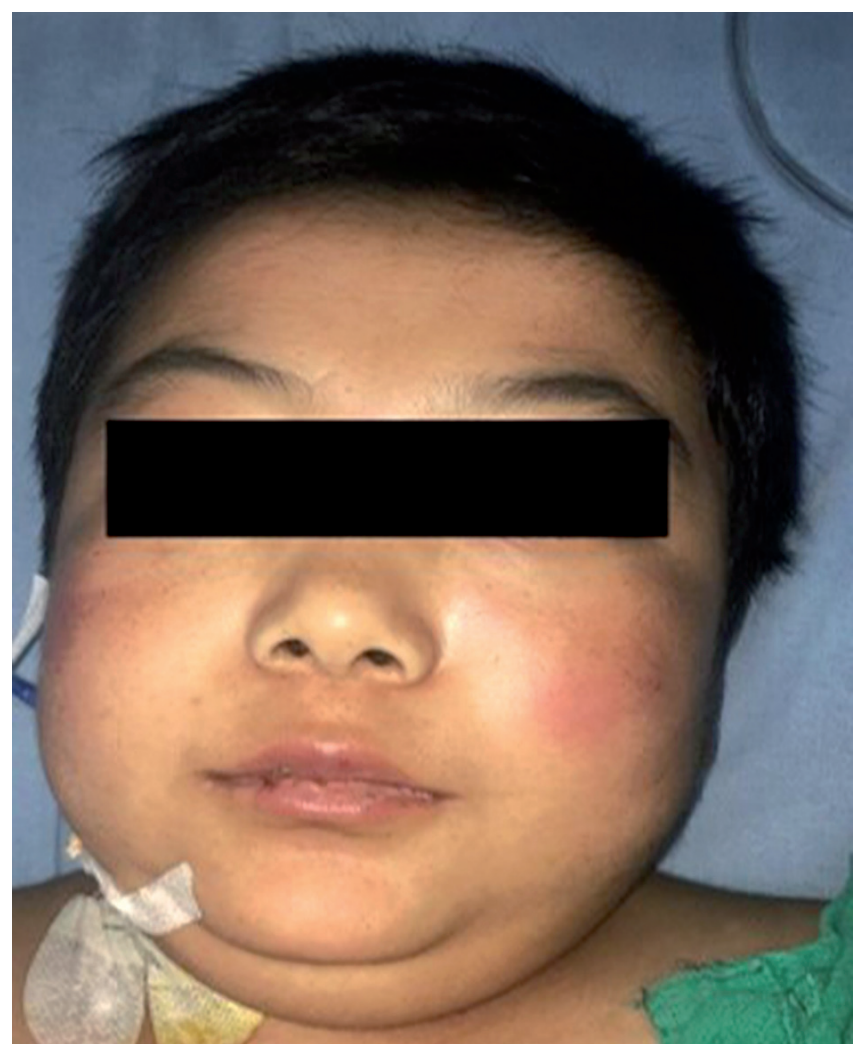

Figure 1. Pre-operative picture of case 1 showing moon-facies, facial plethora, and lentigines seen on the lips, peri-oral area, surrounding the nasal mucosa and on the cheeks broad red-purple striae over the abdomen and thigh, cuticular atrophy, and proximal myopathy. Multiple lentigines and freckles were present all over the face (Figure 1). He had obesity and severe stunting with a height of $137.6 \mathrm{~cm}(-6.48 \mathrm{SDS})$, a weight of $50 \mathrm{~kg}(-1.73 \mathrm{SDS})$, and a BMl of $26.4 \mathrm{~kg} / \mathrm{m}^{2}$. His bone age was delayed (14 years), and testicular volume (TV) was pre-pubertal (bilaterally $3 \mathrm{cc}$ ), with the presence of gynecomastia. (Sexual Maturity Rating: A+P4 TV- 3 cc bilaterally)

Routine investigations revealed dyslipidaemia and hypokalaemia with metabolic alkalosis. His cortisol-dynamics (suggestive of ACTH-independent CS) and other investigations are shown in Table I.

The dual-energy X-ray absorptiometry (DXA) scan showed poor bone mineral density (BMD) with a Z score of -5.8 at the lumbar spine (LS). A contrast-enhanced computed tomography (CECT) of the abdomen showed bilaterally normal adrenal glands.

Bilateral laparoscopic adrenalectomy was performed, and the excised tissue showed multiple nodules surrounded by normal adrenal parenchyma with some areas of atrophy on H\&E staining, with features suggestive of PPNAD (Figure 2). Hypokalaemia resolved completely within days after surgery, and hydrocortisone and fludrocortisone supplementation were started in the post-operative period. There was a reduction of five kilograms of weight after one month of surgery with lightening of striae and reduction in the facial plethora. There was a reduction in the number of anti-hypertensive medications required three months after surgery, and a modest improvement in the lipid profile. Two-dimensional echocardiography was repeated two months after surgery, which showed a remarkable improvement in the ejection fraction (55\%).

\section{Case 2}

An 18-year-old boy, the younger brother of case 1, presented with complaints of weight gain and growth stunting since the age of 10 years, associated with a history of red-purple stretch marks over the abdomen and upper arm. He had hypertension, moon facies, and facial plethora with broad, purple striae over the abdomen and upper arm. He had freckles over the face and lentigines over the upper lip and nose. He had severe stunting with a height of $131.4 \mathrm{~cm}(-7.67 \mathrm{SDS})$, a weight of $38 \mathrm{~kg}(-3.06 \mathrm{SDS})$, and a BMI of $22.0 \mathrm{~kg} / \mathrm{m}^{2}$. His bone age was delayed (14 years), though TV was pubertal with the presence of gynaecomastia (Sexual Maturity Rating: A+ P4 TV-20 cc bilaterally). His routine investigations were unremarkable. The results of his cortisol-dynamics (suggestive of ACTH-independent CS) and other investigations are shown in Table I. The DXA scan showed poor BMD with a Z score of -6.9 at the LS. CECT of the abdomen showed bilaterally normal-appearing adrenals. He was also subjected to bilateral adrenalectomy. The histopathology specimen showed features suggestive of PPNAD. Hydrocortisone and fludrocortisone supplementation were started. He lost six kilograms of weight within one month of surgery with lightening of striae and a reduction in the facial 
Table I. Cortisol dynamics and other investigations of Case 1 and Case 2

\begin{tabular}{|c|c|c|c|}
\hline & Reference range & Case 1 & Case 2 \\
\hline 8 am cortisol & & $553 \mathrm{nmol} / \mathrm{l}$ & $420 \mathrm{nmol} / \mathrm{l}$ \\
\hline 8 am ACTH & & $10 \mathrm{pg} / \mathrm{ml}$ & $11.2 \mathrm{pg} / \mathrm{ml}$ \\
\hline $\begin{array}{l}\text { Over-night dexamethasone } \\
\text { suppression test (ONDST) }\end{array}$ & $<50 \mathrm{nmol} / \mathrm{l}$ & $722.4 \mathrm{nmol} / \mathrm{l}$ & \\
\hline $\begin{array}{l}\text { Low-dose dexamethasone } \\
\text { suppression test (LDDST) }\end{array}$ & $<50 \mathrm{nmol} / \mathrm{l}$ & $702 \mathrm{nmol} / \mathrm{l}$ & $472 \mathrm{nmol} / \mathrm{l}$ \\
\hline $\begin{array}{l}\text { High-dose dexamethasone } \\
\text { suppression test (HDDST) }\end{array}$ & $\begin{array}{l}<50 \% \text { of } 0800 \\
\text { hours value }\end{array}$ & $725.2 \mathrm{nmol} / \mathrm{l}$ & $517 \mathrm{nmol} / \mathrm{l}$ \\
\hline Di-hydroepiandrosterone (DHEAS) & $0.39-4.6 \mathrm{ug} / \mathrm{l}$ & $0.8 \mathrm{ug} / \mathrm{l}$ & $1.3 \mathrm{ug} / \mathrm{l}$ \\
\hline Testosterone & $4.5-28.2 \mathrm{nmol} / \mathrm{l}$ & $1.1 \mathrm{nmol} / \mathrm{l}$ & $12.1 \mathrm{nmol} / \mathrm{l}$ \\
\hline LH & & $0.8 \mathrm{mlU} / \mathrm{ml}$ & $1.1 \mathrm{mlU} / \mathrm{ml}$ \\
\hline FSH & & $6.58 \mathrm{mlU} / \mathrm{ml}$ & $1.9 \mathrm{mlU} / \mathrm{ml}$ \\
\hline Ultrasonography of the abdomen & & Bilateral nephrolithiasis & Bilateral nephrolithiasis \\
\hline Ultrasonography of the neck & & Normal study & Normal study \\
\hline Ultrasonography of the scrotum & & Normal study & Normal study \\
\hline 2D echocardiography & & $\begin{array}{l}\text { Dilated cardiomyopathy (DCMP) } \\
\text { with an ejection fraction (EF) } \\
\text { of } 35 \% \text {. No cardiac myxomas }\end{array}$ & $\begin{array}{l}\text { DCMP with an EF of } 35 \% \text {. } \\
\text { No cardiac myxomas }\end{array}$ \\
\hline
\end{tabular}

plethora. Two-dimensional echocardiography was repeated months after surgery, which showed a remarkable improvement in the ejection fraction (55\%).

\section{Discussion}

We report two interesting cases of CS in a pair of adolescent age-group brothers, due to ACTH-independent PPNAD, as a part of the CC. PPNAD is the most common cause of CS in the adolescent age group, with $>50 \%$ of the cases having $\mathrm{CC}$, characterised by a mutation in PRKAR1A (protein kinase type 1-alpha regulatory subunit) [2]. Although genetic testing could not be done, both the patients fulfilled the clinical criteria for CC; the two major criteria which were satisfied were - the presence of spotty skin pigmentation, and PPNAD, while the presence of positive family history in a first-degree relative fulfilled the supplemental criteria [3].

Both the cases exhibited certain peculiarities typical of PPNAD, while few features were atypical. Both of them had a florid clinical presentation with severe stunting and various features of protein catabolism, whereas PPNAD is usually as-

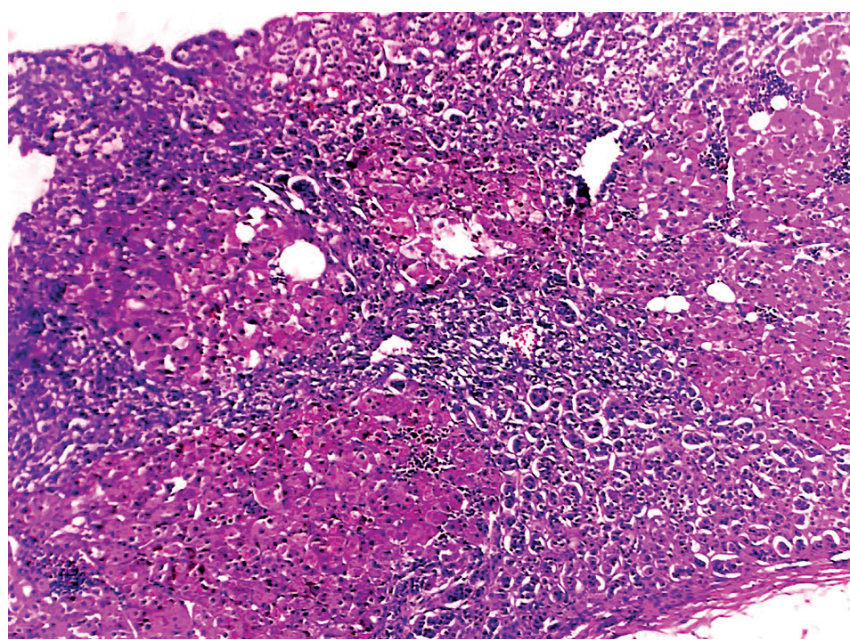

Figure 2. Hematoxylin and eosin staining showing nodules of varying sizes that are surrounded by normal adrenal parenchyma with some areas with atrophy. The cells are composed of small nests and cords and alveolar arrangement of clear and eosinophilic granular cells with lipofuscin pigment deposits is seen 
sociated with a milder presentation. This could probably be attributed to the long duration of the cortisol burden in both cases. There was a suppression of the growth hormone axis and the gonadotropin axis, leading to short stature and delayed puberty, respectively [4].

Chronic cortisol excess had led to poor bone health, metabolic complications in the form of hypertension and dyslipidaemia, and cardiomyopathy. Interestingly, ACTH levels were in the range $10-12 \mathrm{pg} / \mathrm{ml}$ and were not undetectable, as is the case of most adrenal CS. This is postulated to be due to the incomplete suppression of the hypothalamic-pituitary-adrenal (HPA) axis in PPNAD. Another notable finding was the paradoxical increase in cortisol levels on high-dose dexamethasone suppression. This is known to occur in PPNAD due to the presence of glucocorticoid receptors within the adrenal nodules (seen in $70 \%$ of cases) [5].

\section{References}

1. Peng X, Yu Y, Ding Y, et al. Adrenal venous sampling as used in a patient with primary pigmented nodular adrenocortical disease. Transl Cancer Res 2017; 6: 1117-1122. doi: 10.21037/tcr.2017.12.03

2. Choi KM, Seu JH, Kim YH, et al. Cushing's syndrome due to primary pigmented nodular adrenocortical disease - a case report reviews of the literature. Korean J Intern Med 1995; 10: 68-72. doi: 10.3904/kjim.1995.10.1.68

3. Stratakis CA, Kirschner LS, Carney JA. Clinical and Molecular Features of the Carney Complex: Diagnostic Criteria and Recommendations for Patient Evaluation. None 2001; 86: 4041-4046. doi: 10.1210/jcem.86.9.7903
Thus, in an adolescent age-group patient presenting with subtle features of protein-catabolism, low ACTH levels with a paradoxical rise in cortisol on Liddle's protocol, and normal appearing adrenals, a possibility of PPNAD should be entertained. The features may be subtle, so one needs to have a high degree of suspicion. Bilateral adrenalectomy is curative, and the results are gratifying, with an improvement in the BMI and features of protein catabolism. In our patients, the steroidinduced cardiomyopathy was completely reversible, as has been reported previously as well [6]. Carney complex patients need long-term follow-up postoperatively. An annual evaluation should include clinical examination for pubertal progression and growth rate velocity, 2D echocardiography, and thyroid and testicular ultrasound.

4. Greening JE, Storr HL, McKenzie SA, et al. Linear growth and body mass index in pediatric patients with Cushing's disease or simple obesity. J Endocrinol Invest 2006; 29: 885-887. doi: 10.1007/ BF03349191

5. Stratakis CA, Sarlis N, Kirschner LS, et al. Paradoxical Response to Dexamethasone in the Diagnosis of Primary Pigmented Nodular Adrenocortical Disease. Ann Intern Med 1999; 131: 585. doi: 10.7326/0003-4819-131-8-199910190-00006

6. Aydoğan Bi, Gerede DM, Canpolat AG, Erdoğan MF. Cushing's Disease Presented by Reversible Dilated Cardiomyopathy. Case Rep Cardiol 2015; 2015: 1-3. doi: 10.1155/2015/980897 